\title{
A New Maximum Power Point Tracking Based on Neural Networks and Incremental Conductance for Wind Energy Conversion System
}

\author{
Hayat El aissaoui ${ }^{1, *}$, Abdelghani El ougli ${ }^{2}$, and Belkassem Tidhaf ${ }^{1}$ \\ ${ }^{1}$ ENSAO, Mohammed First University, Renewable Energy Embedded Systems and Artificial Intelligence Team (SEERIA), \\ Oujda, Morocco \\ ${ }^{2}$ Faculty of Science Dhar El Mahraz, Sidi Mohamed Ben Abdellah University, Computer Science, Signal, Automation and \\ Cognitivism Laboratory (LISAC), Fez, Morocco
}

\begin{abstract}
This work presents a new Maximum Power Point Tracking (MPPT) for the connection of the wind turbine system (WT) to the synchronous permanent magnet generator (PMSG). To search the maximum power of the wind turbine, we have proposed a new MPPT which combines two techniques: Artificial Neural Network (ANN) and incremental conductance (IncCond) method. The advantage of ANNbased WT model method is the fast MPP approximation base on the ability of ANN according the parameters of WT that used. The advantage of IncCond method is the ability to search the exactly MPP based on the feedback voltage. In our case the ANN is employed to predict the maximum voltage of the WT, under different values of wind speed, and the control of DC-DC boost converter operation is executed by applying incremental conductance (IncCond) technique. The proposed system includes a wind turbine associated to a permanent magnet synchronous generator (PMSG), a rectifier and a DC-DC converter with MPPT control. The proposed algorithm is tested under MATLAB SIMULINK.
\end{abstract}

\section{Introduction}

Today, the world is facing a range of especially difficult energy problems, which have become even more difficult in recent years, as a result of the rapid increase in energy consumption. In addition, in comparison to the production of energy, world energy consumption is growing rapidly because of population growth, changing and improving lifestyles and more industrialization. The International Energy Agency predicts that global energy demand will increase by $44 \%$ between 2006 and 2030 . [1]

Due to rising power demand and the depletion of fossil fuels such as coal for electricity generation, the usage of renewable energy resources has expanded in recent years. Furthermore, the subject of climate change is raising concern, and as a result, several legislation to minimize carbon dioxide (CO2) emissions has been proposed. Solar and wind energy are the most common renewable energy sources.

By maintaining the best stable voltage across the load, MPPT control algorithms may be used to obtain the maximum power from available wind. In previous studies, a variety of MPPT techniques for Wind Energy Conversion System have been used, including the Hill Climbing Search (HCS) algorithm, Incremental and Conductance Method (INC), Perturb and Observe (P\&O), and Fuzzy Logic.[2]
One of the techniques of artificial intelligence used for the tracking of the point of maximum power them is the artificial neural network. The main advantage of this algorithm is that it eliminates the need to solve the complex mathematical problem, as well as the fact that the outputs are obtained in a fraction of the time and without oscillations.

The advantage of using an ANN is the fast approximation of the MPP and the ability of the ANN to adapt to the characteristics employed. The IncCond approach has the advantage of being able to find the exact MPP.

This paper presents a novel method for determining the maximum power point for a wind energy conversion system.

In fact, we present a new MPPT that is primarily based on the incremental conductance approach (INC) and Artificial Neural Networks (ANN), allowing us to extract the maximum power from the wind turbine.

The concept is to employ an ANN to determine the maximum voltage of the WT using various wind speed values, while a DC-DC boost converter will be controlled by an incremental conductance.

A wind turbine, a permanent magnet synchronous generator (PMSG), a rectifier, and a DC-DC converter with MPPT control are all part of our system.

\footnotetext{
* Corresponding author: hayatel89@gmail.com
} 
The proposed approach is more efficient in terms of tracking the MPPT and extracting the maximum power of a WT, according to our observations.

The following is a diagram of the suggested model:

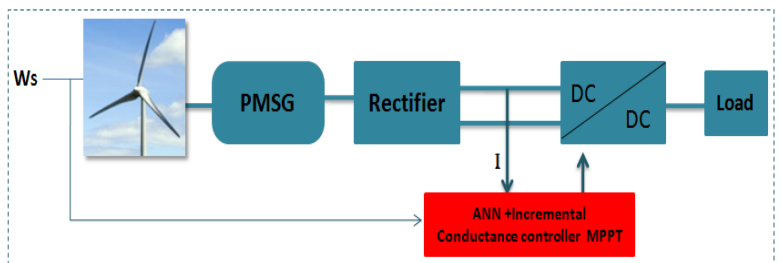

Fig. 1. Schematic of ANN and Fuzzy Logic Based on PMSG.

\section{Model of a wind turbine}

There are many published studies concerning wind turbines and wind generators. The WT model suggested in this work is based on the characteristics of wind speed versus WT power output.

The wind turbine is a system that converts the kinetic energy of the wind into mechanical work. Based on the calculation relations, it is possible to calculate the value of the aerodynamic power of the wind turbine as follows: [3]

$$
P m=C p(\lambda, \beta) \frac{\rho * A * V^{3}}{2}
$$

Where

- Pm: output mechanical power of the turbine

- $\rho$ is the air density $\left(\mathrm{kg} / \mathrm{m}^{3}\right)$.

- $\mathrm{Cp}(\lambda, \beta)$ is the performance coefficient of the turbine.

- $\mathrm{A}=\pi * \mathrm{R}^{2}$ The turbine swept area.

- V: the wind speed $(\mathrm{m} / \mathrm{s})$.

- $\lambda$ : the tip speed ratio .

$-\beta$ : the blade pitch angle (deg).

The relationship between the wind speed and the rotor speed is defined as tip speed ration $\lambda$ :

$$
\lambda=\frac{\mathrm{R} * \omega}{v}
$$

Where:

- $\mathrm{R}$ : The turbine ratio $(\mathrm{m})$.

- $\omega$ is the turbine angular velocity $(\mathrm{rad} / \mathrm{s})$.

The power coefficient is as below:

$$
\begin{gathered}
C p(\lambda, \beta)=0.22\left(\frac{116}{\lambda i}-0.4 \beta-5\right) e^{\frac{-21}{\lambda i}} \\
\frac{1}{\lambda i}=\frac{1}{\lambda+0.08 \beta}-\frac{0.035}{\beta^{3}+1}
\end{gathered}
$$

The aerodynamic torque is presented as follows:

$$
T=\frac{P m}{\omega}=\frac{1}{2 \lambda} \rho \pi R^{3} V w^{2} C p(\lambda, \beta)
$$

The characteristic of power coefficient is presented as follow:

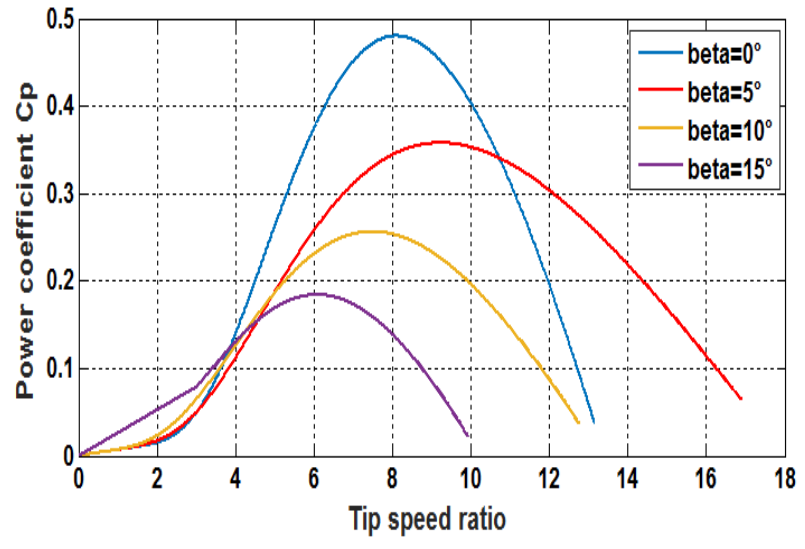

Fig. 2. Characteristics of Power Coefficient.

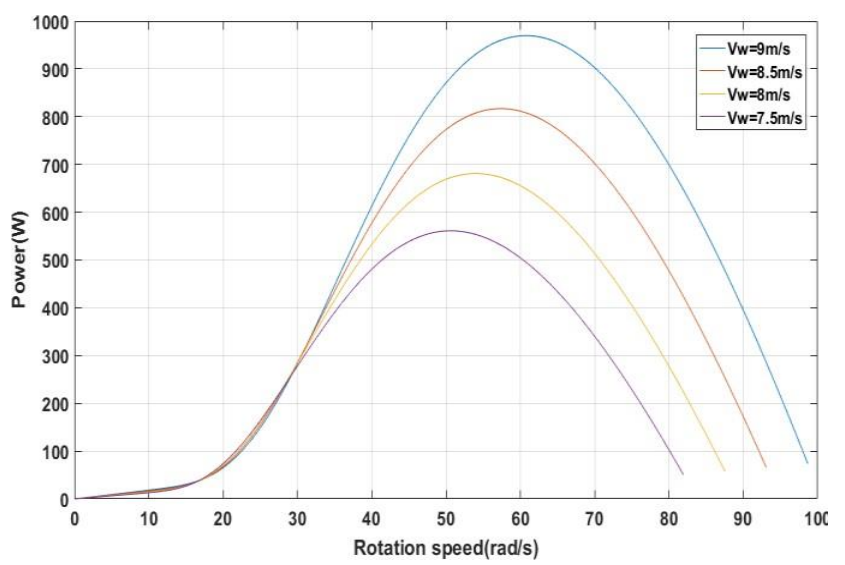

Fig. 3. The Power Curves under Different Wind Speeds $(\beta=0)$.

The Turbine Generator's parameters are listed as follows: 
Table 1. WT generator system characteristics.

\begin{tabular}{|c|c|}
\hline Characteristics & Values \\
\hline Rated Voltage & $90 \mathrm{~V}$ \\
\hline Rated Power & $1000 \mathrm{~W}$ \\
\hline Synchronous inductance & $1 \mathrm{mH}$ \\
\hline Rated Current & $4.8 \mathrm{~A}$ \\
\hline Number of poles & 8 \\
\hline Synchronous resistance & $1.13 \Omega$ \\
\hline Friction coefficient & 0.006N.m.s/rad \\
\hline Magnetic flux & $0.16 \mathrm{~Wb}$ \\
\hline Moment of inertia & $0.005 \mathrm{~N} . \mathrm{m}$ \\
\hline Blade length & $1.2 \mathrm{~m}$ \\
\hline Air density & $1.2 \mathrm{~kg} / \mathrm{m} 3$ \\
\hline
\end{tabular}

\section{Converter modeling}

A boost converter, or parallel switching power converter, is a switching power system that converts one DC voltage into another higher value DC voltage.

The functioning of a Boost converter can be divided into two different phases according to the state of the $\mathrm{S}$ switch.

A phase of energy accumulation: when the switch $\mathrm{S}$ is closed, this leads to an increase in the current in the inductance and consequently the storage of a quantity of energy in the form of magnetic energy. The diode D is then blocked and the load is then disconnected from the power source.

When the switch is open, the inductor is in series with the generator and its e.m.f. is added to the generator's e.m.f. (boost effect). The current passing through the inductor then passes through the diode $\mathrm{D}$, the capacitor $\mathrm{C}$ and the load R. Consequently, the energy accumulated in the inductor is transferred to the capacitor. [ 4]

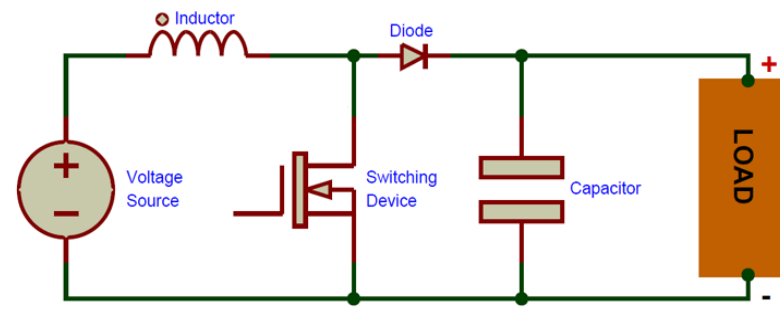

Fig. 4. Boost Converter Configuration.

When a boost converter operates in continuous conduction mode, the current IL passing through the inductor will never be zero.

The output voltage is calculated as follows: [5]

$$
\text { Vout }=\frac{1}{1-D} \text { Vin }
$$

Where:

- Vout: The output voltage.

- Vin: The input voltage.

- D refers to the duty cycle.

With this last expression, we can clearly see that the output voltage is always higher than the input voltage.

The inductor of the boost converter is calculated by:

$$
L=\frac{\operatorname{Vin} \cdot D}{\Delta I L \cdot f}
$$

The capacitor of the boost converter is determined by:

$$
C=\frac{I_{0} \cdot D}{\Delta V_{\text {out }} \cdot f}
$$

Where

- $\triangle \mathrm{IL}$ : The approximate inductor ripple current.

- $f$ : Switching frequency.

- $\Delta$ Vout : The estimated output ripples voltage.

\section{The proposed MPPT technique}

Many distinct MPPT approaches have been thoroughly examined in various studies. The next sections describe two methods that are used in this new method.

We propose a new power tracking approach based on Incremental Conductance Method (INC-Cond) and Artificial Neural Networks to find the maximum power produced by a wind turbine (ANN), as shown in Figure 5.

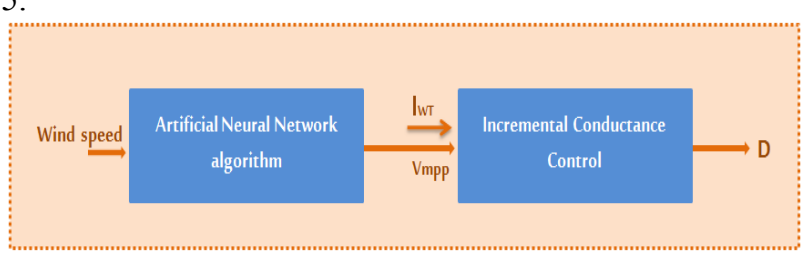

Fig. 5. Block Diagram Developed MPPT.

In this paper, two steps are applied to keep track the MPP of the WT. 
The ANN is employed in the first stage to determine the Estimated Optimal Voltage Value (VMPP) for each wind speed value.

The maximum voltage value of the wind turbine associated with any given wind speed is estimated using ANN. It calculates the value of VMPP using a database that combines each wind speed with the accompanying Vout voltage. The INC-COND method is used in the second phase to calculate the Duty cycle value.

\subsection{ANN based MPPT algorithm}

An artificial neural network or Neural Network is a computer system inspired by the functioning of the human brain to learn.

An artificial neural network aims to simulate human intelligence, using neurons that imitate the functioning of the human brain. Artificial neurons are integrated into software and allow machines to become autonomous, through the technology of artificial intelligence (AI).

In general, a neural network is based on a large number of processors operating in parallel and organized in thirds. The first stage receives raw information inputs, much like the optical nerves of a human being when processing visual signals. Thereafter, each stage receives the information outputs of the previous stage. [6]

ANNs are systems made up of at least two layers of neurons, an input layer and an output layer, with hidden layers included in most cases. The artificial neural network must have additional layers if the task is difficult. [7]

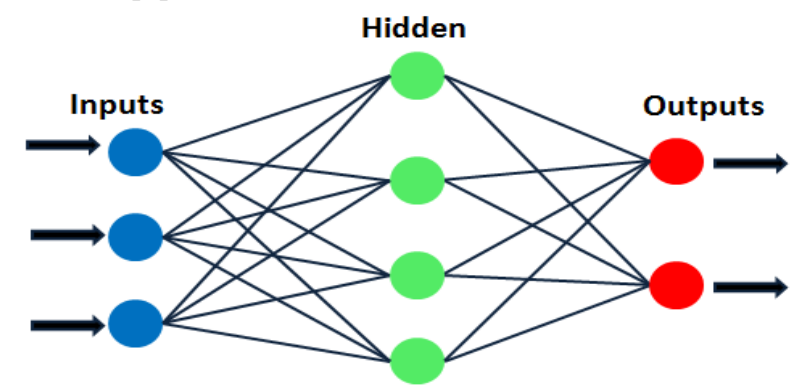

Fig. 6. ANN Diagram.

In this contribution, $\mathrm{X} 1$ signifies the wind speed value, which is the ANN's input, and Y1 signifies the output VMPP (optimal voltage).

The artificial neural network is generated using a Matlab code and the training of a database (wind speed, V).

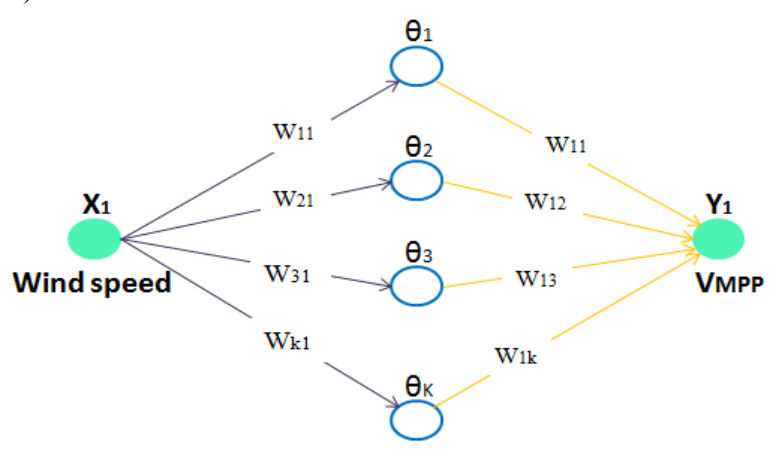

Fig. 7. $V_{M P P}$ Prediction Using ANN.
In our case, the optimal number of neurons in the first layer is forty, whereas the second layer contains one purelin neuron, one neuron in the input layer, and one in the output layer.

\subsection{Incremental conductance method}

The IncCond approach overcomes the shortcoming of perturb and observe method in tracking peak power under rapidly changing atmospheric conditions.

The principle of this algorithm is based on the knowledge the value of the conductance $G=I / V$ and the increment of the conductance $(\mathrm{dG})$ to deduce the position of the operating point in reference to PPM. If the increment of conductance $(\mathrm{dG})$ is higher than the opposite of the conductance $(-\mathrm{G})$, the duty cycle is decreased. On the other hand, if the conductance increment is less than the opposite of the conductance, the duty cycle is increased. the duty cycle is increased. This process is repeated until reaching the MPP.[8]

In our case the process of the INC-Cond technique is described as follows:

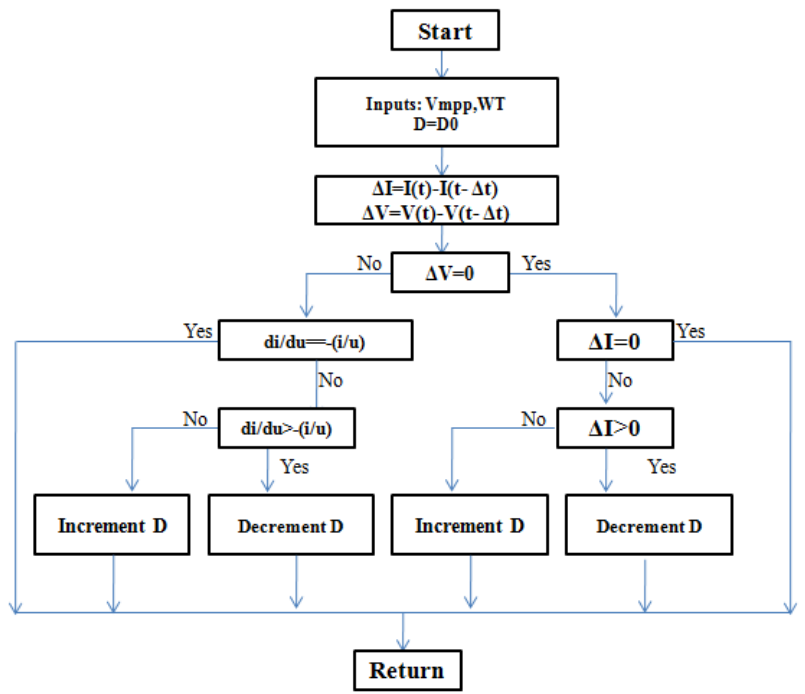

Fig. 8. IncCond Algorithm.

The INC-Cond controller is used to indicate the value of D based on the inputs VMPP (voltage) and Iwt (current).

\section{Results and discussion}

The WT system is composed of wind energy conversion system, based on a synchronous permanent magnet generator, a rectifier, and a boost converter, as shown in figure 9 .

To extract the maximum power, we propose a new approach based on two blocks: artificial neural networks and Incremental Conductance. This section presents the results of the simulation made under Matlab. 


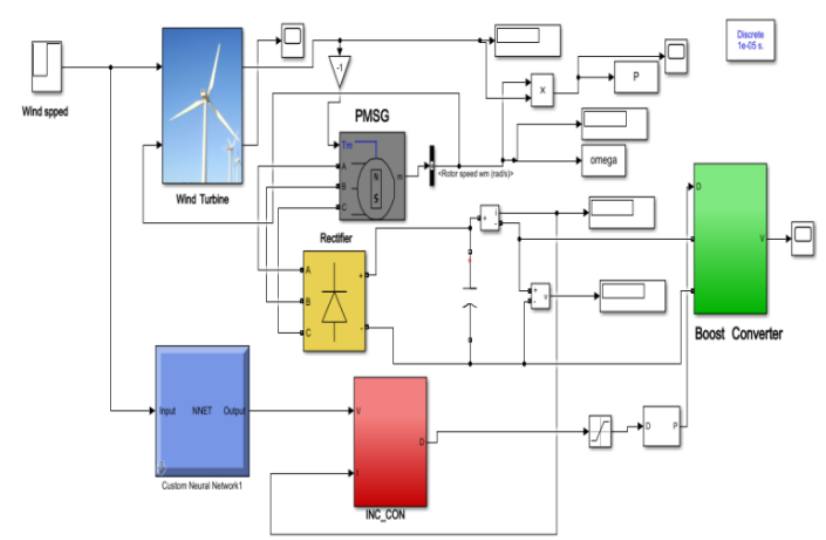

Fig. 9. ANN-IncCond Model in Matlab/Simulink.

Figure 10, 11 show respectively the output power of the WT system, the power coefficient, under wind speed $=7.9 \mathrm{~m} / \mathrm{s}$.

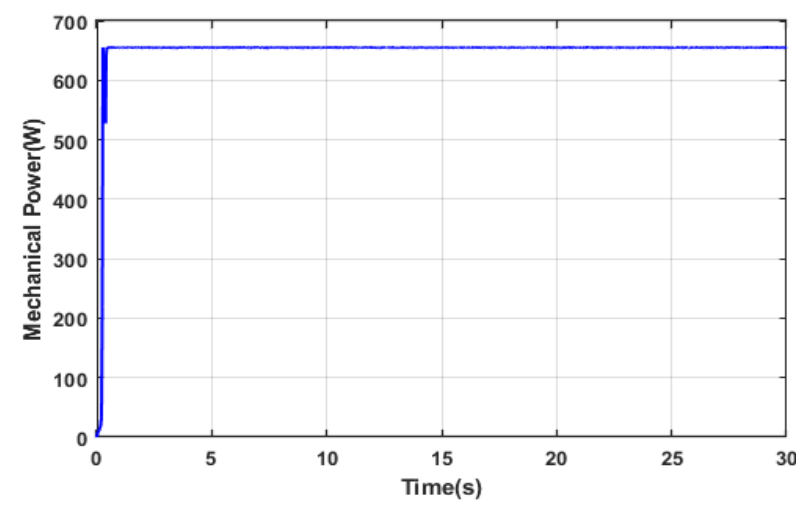

Fig. 10. The Output Mechanical Power for $7.9 \mathrm{~m} / \mathrm{s}$.

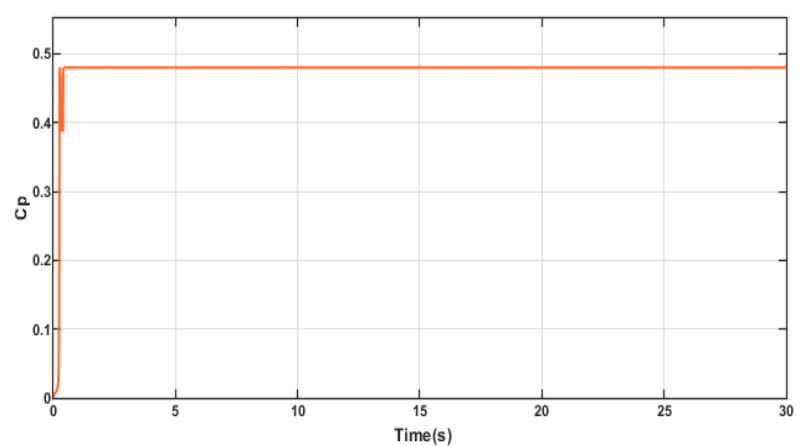

Fig. 11. Power Coefficient for $7.9 \mathrm{~m} / \mathrm{s}$.

Figure12, 13 show respectively the output power of the WT system, the power coefficient, under wind speed $=$ $8.5 \mathrm{~m} / \mathrm{s}$

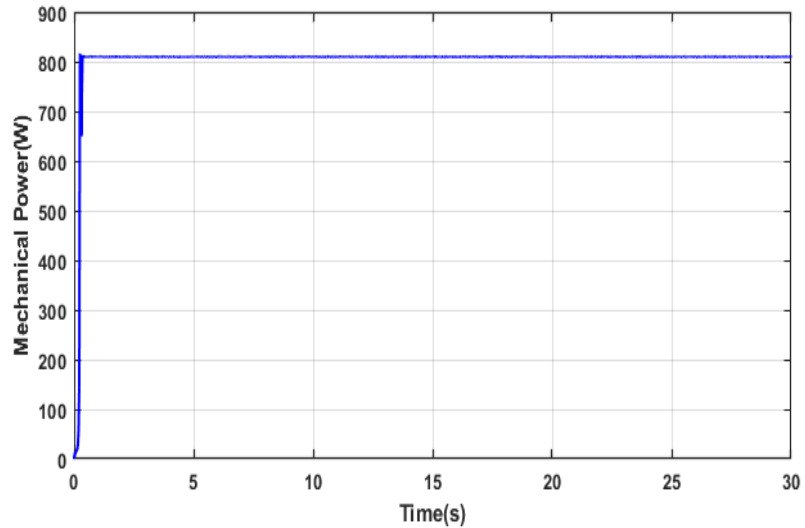

Fig. 12. The Output Mechanical Power for $8.5 \mathrm{~m} / \mathrm{s}$.

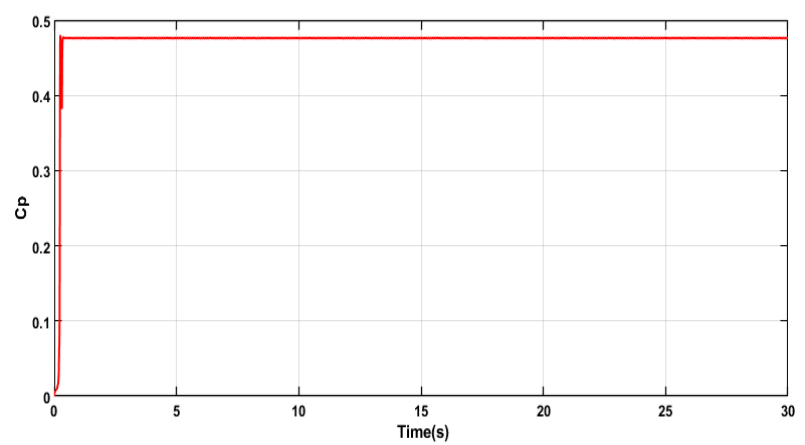

Fig. 13. Power Coefficient for $8.5 \mathrm{~m} / \mathrm{s}$.

From these results, we can see that the system has been able to track and reach its $\operatorname{MPP}(\mathrm{Cp}=0.48)$ under different values of wind speed.

\section{Conclusion}

We proposed a new maximum power point tracking approach for a wind power system to improve the efficiency of the wind power system by tracking the MPP, through the boost converter control.

The proposed method is based on an artificial neural network and incremental conductance. The power produced by the wind system depends on the wind speed.

From the results obtained from the simulation and by comparing these results with the theoretical results, we can deduce that the proposed technique is effective in the sense of tracking the maximum power point produced by the wind system while exploiting the advantages of both ANN and INC-COND techniques.

The proposed MPPT approach is tested under different values of wind speed using MATLAB /SIMULINK.

\section{References}

1. M.Merchaoui, M.Hamouda, A.Sakly, M.F.Mimouni, "Fuzzy logic adaptive particle swarm optimization based MPPT controller for photovoltaic systems," the institution of engineering and technology IET, 14(15), 2933-2945,( 2020). 
2. R.Tiwari, R.Babu, "fuzzy logic based MPPT for permanent magnet synchronous generator in wind energy conversion system," IFAC-Papers OnLine, vol. 49, no 1, pp. 462-467, (2016).

3. Wang, C. N., Lin, W. C, Le, X. K., "Modeling of a PMSG Wind Turbine with Autonomous Control," Mathematical Problems in Engineering, (2014).

4. www.electrosup.com

5. Duka, I., \& Noble, C. W, "High frequency DC/DC boost converter," (2011).

6. www.lebigdata.fr

7. Gowri, J. K., \& Popuri, M. C. "Neutral Networks Based Maximum Power Point Tracking (MPPT) Of Wind Power Generation," The International Journal of Scientific Development and Research (IJSDR), Vol.5, no 2, 2020.

8. Dzung, P. Q, Lee, H. H, N. T. D, "The New MPPT Algorithm using ANN-Based PV," IFOST, pp. 402407, (2010). 